\title{
Simplified Approach New for Dielectric Heat Control
}

\author{
Anuradha Tomar. and D.S. Tomar
}

\begin{abstract}
This paper proposes a Dielectric heat control via solid state medium frequency generation technique and its optimization for use in Stone cutting Industries. Dielectric heating is the phenomenon in which radio wave or microwave electromagnetic radiation heats a dielectric material, especially as caused by dipole rotation. The essential advantage of dielectric heating resides in the generation of heat within the material to be heated. In comparison with more conventional heating techniques (hot air, infrared) in which the material is heated via the outer surface, dielectric heating is much more rapid.
\end{abstract}

\author{
Index Terms - Dielectric heat Control, Medium Frequency, \\ and Stone cutting.
}

\section{INTRODUCTION}

In recent years, some sorts of ultrasonic-frequency highpower inverter appliances used widely for metal heat treatment applications, such as surface hardening, forging, annealing, brazing, tempering, and soldering, have been actively introduced into industrial electromagnetic heat processing plants [1]-[2].With the great advances of power semiconductor switching devices and micro electronics control processing circuits, much more attention in highfrequency power electronics has been paid to further research and developments of cost-effective high-frequency power conversion circuits using new power semiconductor devices and systems for industrial induction heating and melt.A variety of high-frequency resonant and quasiresonant inverter topologies using high-frequency highpower static induction transistors (SIT's) developed in Japan are capable of delivering high power in the frequency range from 10 to $500 \mathrm{kHz}$, or higher [3]-[5].

Heat treatment processes are commonly used in stone cutting industries, where diamond cutting tool bits are formed by compacting, say three layers of metal powder or granules with desired composition and on application of high compacting pressure, moulds of tool bits are made. These moulds are heated in proportion to temperature rise and high compacting pressure is applied simultaneously. At temperature rise of $900^{\circ} \mathrm{C}$, a pre-defined compacting pressure is applied and hold for 4-5 sec. Then cooling

Manuscript submitted on May 14, 2009. This work was supported in part by the Prabha Electronics and Automation, Ajmer

Anuradha Tomar is with the National Institute of Technology, Hamirpur, H.P- 177005 INDIA ( phone: 0145-2440519; e-mail: eranu28@ gmail.com).

D.S Tomar, was with the Hindustan Machines Limited and now is associated with Prabha Electronics and Automation, Ajmer (Rajasthan)-305001. process starts and pressure also reduces proportionally.

For above application a local spontaneous, reliable heat source surrounding the mould is needed, which should have infinitely variable heat control, fast in temperature rise, minimum energy loss and economically viable is warranted. In addition to all above requirements, following points are also considered here: a) There should be no effect on 3phase power supply of plant in terms of fluctuations in voltage, frequency, power factor generation of harmonics and electromagnetic interference. b) All necessary protection for safety of system, machine, personnel, job etc. is to be inbuilt in various sections of projects.

\section{SYNTHESIS OF COMPONENTS}

General block diagram for representing the whole system is shown in figure 1.Now we will discuss each individual component as follows:

\section{A. A. D.C. power unit}

Control Card is meant for process control, safety and monitoring. It was designed incorporating the 0 to $10 \mathrm{~V}$ control command using operational amplifier IC LM348N as a unity buffer. Ramp control ranges from 0 to 30 seconds. An Error amplifier was generated via algebraic summation of command and feed back. It consists of a Current control amplifier stage and Close loop control feedback. (0-10 V) output signal of amplifier was used for firing SCR. Also, fault generation logic is used here for - No feed back, time dependent over load, instantaneous over current Under/Over voltage limits. Temperature sensing of SCR mounted heat sink is done via thermo-state. External start-stop logic is implemented for enable \& disable the process and pulse inhibit control for fast switching off, to clear short circuit current level, which is much faster than semi conductor fuses.LED indication are used to indicate for above healthy / faulty status.

A synchronizing $12 \mathrm{~V}$ AC signal is taken as reference, passed to operational FET amplifier TL-081 IC to generate square wave and as a clock given to IC 4046 for phase lock loop control, and sequential 6 pulse set is generated using counter IC 4017. On R-C phase splitting via buffer given to comparator LM339 to get 6 pulse set after smoothening via Schmitt trigger IC4093.

\section{B. B. A.C Unit}

A common control card as described earlier is also used with this unit. Second frequency generation based on PWM IC 3524 is used with bia-stable Q \& Q outputs. Adjusting pot for pulse width control and frequency variation are available for matching transformer switching load which in inductive in nature. 


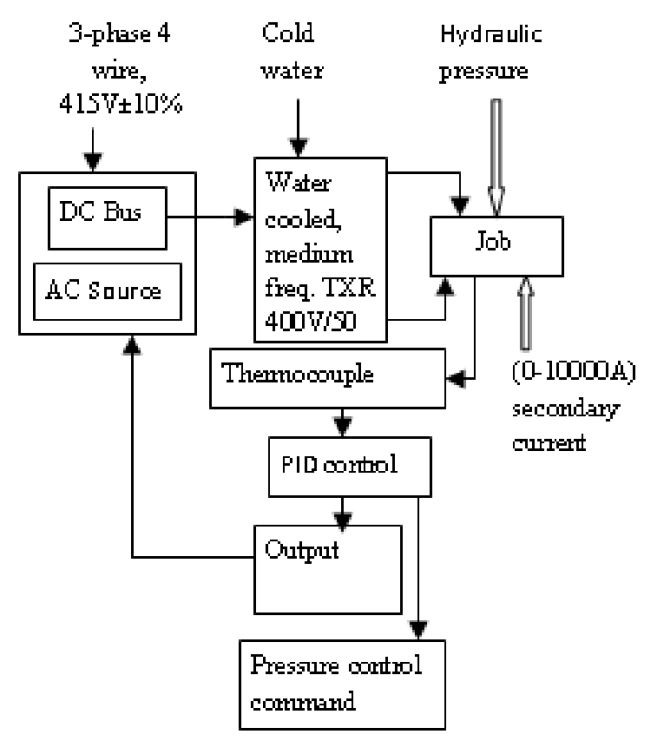

Fig. 1 Block diagram

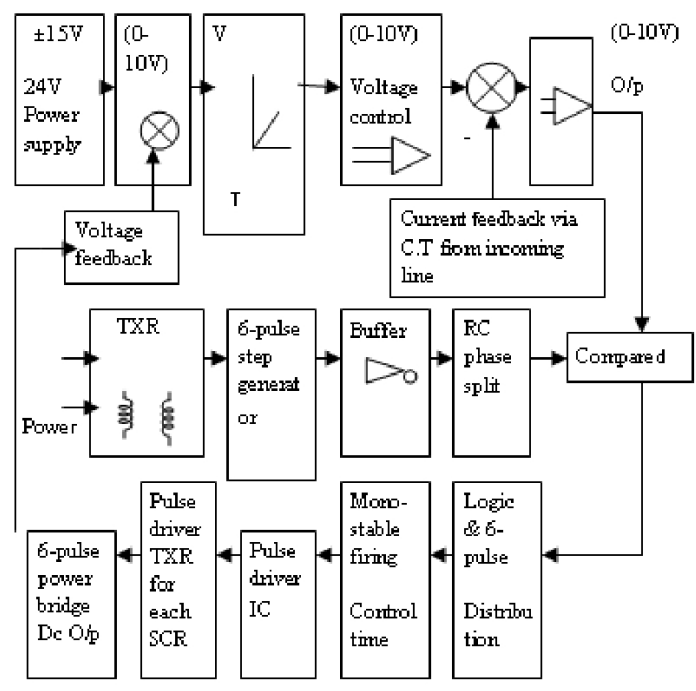

Fig. 2 6-pulse Synchionititig and firing control circuit

These frequency pulses are distributed into left and right channels to coordinate Power Bridge switching in such a way that power devices of any one side, across DC bus are not triggered simultaneously or having overlap time. An inbuilt switching logic is made in such a way that only one set of them is switched on at a time. We must consider IGBT latch up in inductive load switching, as challenging task, to ensure reliable working. A third card consisting of 4 driver sets for each IGBT was developed to ensure control $\&$ and power isolation and avoiding possibility of IGBT latch up. Capacitive Bank consisting of 84 nos. capacitors, were used in series with transformer primary winding to curve down reactive power. All IGBT devices were mounted on heat sink fitted with thermo-state and cooling fan, along with RC network for each device.

A EUROTHERM UK based company make PID was used which is having programmable Inputs and Outputs and based on thermo-couple (Type K, up to $1000^{\circ} \mathrm{C}$.) algorithm, a temperature based inversely proportional $(0-10 \mathrm{~V})$ signal was used to control DC bus level and hence to regulate transformer input primary power.

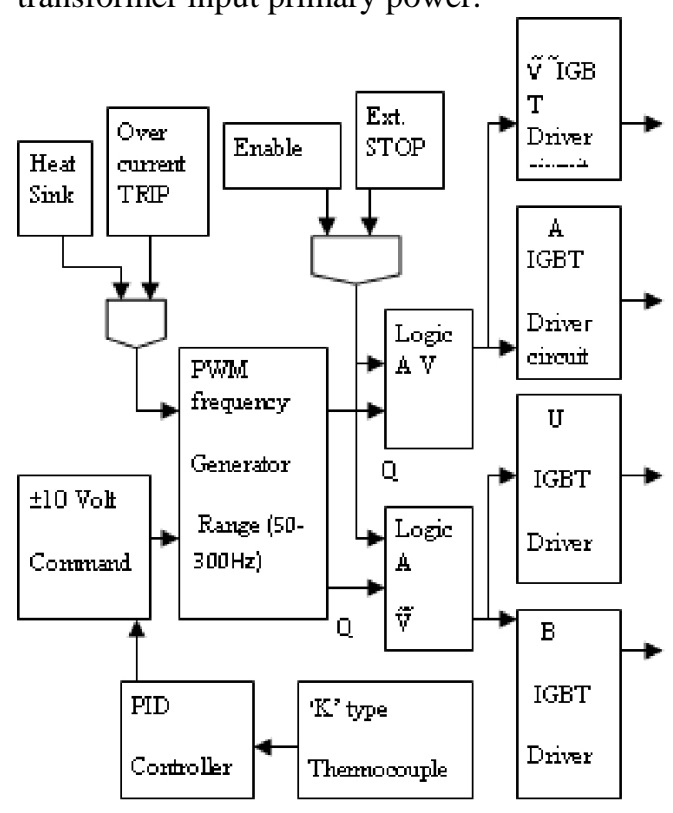

Fig. 3 Block Diagam of $A . C$ Unit

When you submit your final version, after your paper has been accepted, prepare it in two-column format, including figures and tables.

III. SPECIAL CONSTRUCTION POINTS

In this graphite die block is used and hydraulic pressure with different values of P1, P2, and P3 are applied in three stages at different temperature values.

Transformer primary is water cooled and copper foils are used for $10 \mathrm{~K}$ Amp. flow, which are flexible. Special vaccum is created by exhaustive to take out fumes during heating.3-phase inductor at incoming 2-phase power supply is added for harmonic control. Addition of capacitive bank improves $\geq 30 \%$ efficiency in heat up time. Total size occupied is $2 \times 2.5 \times 2$ meter.

\section{OPERATION}

Metal power based moulds with layers ads per desired composition of weight are made in a separate machine. These mould bits are arranged in graphite based die, which act as a job enclosure (declared as job).

The job is put on a hydraulic platform, for perfect mounting and contact closure two wires of each part are shorted, and with this green signal cycle is initiated. D.C. bus is accelerated in a ramped manner and simultaneously power transformer is also energized and due to secondary high value current, job starts heating up.

PID controls the D.C. level as per temperature achievement. Also in 3 stages PID gives output signals to energize hydraulic solenoids to exert preset value of pressures.

The mould metallurgical changes do occur. At $9000 \mathrm{C}$. temperature the job is hold under certain compacting pressure, and after 5-6 seconds, cooling down process starts, the hydraulic pressures on job are also removed in stages. On opening, the moulds are converted into tool bits, having desired metal composition, structure and hardness and 
declared as diamond cutting tool bits used in marble/granite slabs cutting.

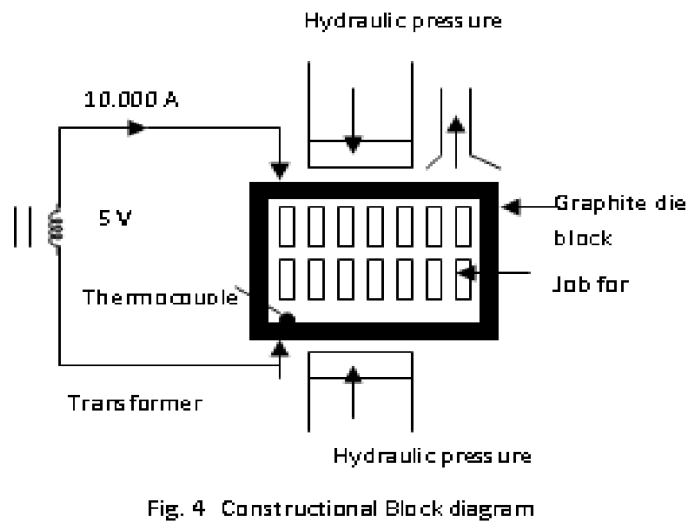

V. EXPERIMENT RESULT

At higher temperature graphite resistance value increases, as a result higher voltage is applied to keep constant heat.

Table 1: Temperature At Constant Heat

\begin{tabular}{|l|l|l|l|l|}
\hline $\begin{array}{l}\text { Temperature } \\
(\circ \mathrm{C})\end{array}$ & $\begin{array}{l}\text { Power } \\
\text { Demand } \\
\text { (Percent) }\end{array}$ & $\begin{array}{l}\text { DC } \\
\text { Volt }\end{array}$ & $\begin{array}{l}\text { Load } \\
\text { Amp. }\end{array}$ & $\begin{array}{l}\text { Input } \\
\text { Power } \\
\text { VA }\end{array}$ \\
\hline 38 & 100 & 540 & 40 & 24300 \\
250 & 100 & 540 & 45 & 25380 \\
400 & 100 & 540 & 47 & \\
500 & 100 & 540 & 47 & \\
640 & 40 & 440 & 45 & \\
750 & 32 & 390 & 38 & \\
800 & 28 & 350 & 30 & \\
900 & 10 & 150 & 18 & \\
\hline
\end{tabular}

\section{CONCLUSION}

In this paper Dielectric heat control via solid state medium frequency generation technique has been proposed for stone cutting purpose in Industries. This technique has an distinguishing factor that one cycle time is approximately 10-15 minute where as the power factor of plant remains around 0.94-0.98. Over all capital investment is approximately $3.00 \mathrm{Lac}$ for this heat control project. Hence return on investment on investment is within 18 months. It is concluded from implementation and result analysis that as a whole system is reliable and it is economically competitive to produce components based on this technique.

\section{REFERENCES}

[1] E. J. Davies, "Conduction and induction heating," in Inst. Elect. Eng. Power Engineering Series II. Stevenage, U.K.: Pereginus, 1990.

[2] C. J. Erickson, Handbook of Electrical Heating for Industry. Piscataway, NJ: IEEE Press, 1995.

[3] Okuno, H. Kawano, A. Kojina, J. M. Sun, and M. Nakaoka, "Industrial

[4] induction-heating power appliance using voltage-fed zero current switching high-frequency inverter with phase-located loop control scheme," in Proc. IEEE-IAS Int. Appliance Tech. Conf., May 1996, pp. 381-387.

[5] J. Davies and P. Simpson, Induction Heating Handbook. New York: McGraw-Hill, 1979.

[6] Okuno, H. Kawano, M. Hayashi, H. Yasutsune, E. Hiraki, and M. Nakaoka, "Phase-lock loop operated load-resonance inverter using static induction power transistor and its practical characteristic evaluations," in Proc. IEEE-IAS Conf. Emerging Technology, May 1995, vol. 1, pp. 1-7.

[7] Eugene P.Mierzwinski(1991),Integrated Furnace Control",IEEE Transaction On Industry Applications, No.2, Vol.27.March/April.

[8] D.Melaab,o.Longeot(1993), an introduction control of heat treatment by the measure of power ,IEEE transaction on Magentics, Vol. 29,No.2,March.
Ms. Anuradha Tomar, received her B.E degree in Electronics Instrumentation \& Control Engineering with "Honours" from Institute of Engineering. \& Technology, Alwar (Raj) in 2007. Presently she is pursuing her M.Tech in Advance Power System, from N.I.T, Hamirpur (H.P.). She is associated with projects like Energy Conservation using Automation, D.C Drives \& also associated with "Prabha Electronics Automation". Her areas of interest are Design of Earthing Systems, Control Systems like SCADA, PL 